\title{
LA CALIGRAFÍA EN EL DISEÑO DE ESTILOS GRÁFICOS PARA EL CINE DE ANIMACIÓN: GRANGEL STUDIO Y EL EJEMPLO DE CORPSE BRIDE
}

Alberto Carrere

Universitat Politècnica de València

Data recepción: 2016/05/12

Data aceptación: 2017/04/24

Contacto autor: acarrere@upv.es

ORCID: https://orcid.org/0000-0001-5933-2278

\section{RESUMEN}

El dibujo está en la base del estilo gráfico de una película de animación. Por su parte, la caligrafía se relaciona con el dibujo y la pintura por la gestualidad del trazo, ese índice tan significativo del signo plástico en arte y comunicación visual. Además, la caligrafía tiene un lugar diferenciado en la historia del diseño gráfico y la escritura. Grangel Studio crea personajes y estilos gráficos para DreamWorks, Sony Animation o Warner Bros, en los que la caligrafía tiene un papel relevante. Con ese marco teórico y referentes, el artículo indaga cómo la caligrafía participa en el estilo de las películas, con el caso paradigmático de Corpse Bride (2005), donde las caligrafías del filme y promociones, junto al dibujo de personajes, colaboran con el universo del relato, afín a las recreaciones neogóticas del director Tim Burton.

Palabras clave: caligrafía, tipografía, estilo, Corpse Bride, gótico

\section{ABSTRACT}

Drawing is the basis of the graphic style of animated films, while calligraphy relates to drawing and painting through the nature of its strokes, that meaningful indicator of the plastic sign in visual arts and communication. Calligraphy also occupies a prominent place in the history of graphic design and writing. Grangel Studio creates graphic characters and styles for DreamWorks, Sony Animation and Warner Bros, a process in which calligraphy plays an important role. Drawing on this theoretical framework and references, this article examines how calligraphy contributes to the style of these feature films, taking as a case in point Corpse Bride (2005), where the calligraphy used in the film and promotional artwork and the rendering of the characters work as one with the story world, in the manner of the neogothic productions of the director Tim Burton.

Keywords: calligraphy, typography, style, Corpse Bride, gothic

\section{Introducción}

Para Giorgio Vasari, el disegno, padre de las tres artes renacentistas, arquitectura, pintura y escultura, proviene del intelecto y no es sino una expresión del "concetto, che si ha nell'animo", aquello que desde la mente se hubiera "immaginato e fab- bricato nell'idea" ${ }^{1}$. En su época el disegno era el dibujo, pero también la intención, el proyecto, el propósito². Esa aspiración del Cinquecento sigue vigente en las actuales películas de animación, cuyos estilos gráficos tienen origen en el dibujo, pero además suponen la intención e integración 
de diversos medios: ilustración manual y digital, escultura, cine, programación informática, etc.

La expresión visual de los textos, el instrumento más específico del diseño gráfico, puede igualmente contribuir y participar en este tipo de proyectos. Su estudio, en la variante de la escritura caligráfica, tiene un interés diferenciado porque la caligrafía se relaciona con el dibujo y la pintura por la gestualidad del trazo, ese índice tan significativo del signo plástico ${ }^{3}$ en arte y comunicación visual. A este parangón en la función estética, conviene añadir el lugar que ocupa la caligrafía en la historia del diseño gráfico y la escritura. Por ello, se han analizado trabajos de Grangel Studio, empresa dedicada a la creación de estilos y personajes para producciones internacionales de cine de animación que da gran importancia al tratamiento visual de los textos, incorporando en todos sus proyectos opciones de logotipos del título, personajes y otras posibles denominaciones secundarias, tanto en relación a la película como a su promoción comercial. El principal responsable de esa labor es Carles Burgès, uno de los socios fundadores de Grangel Studio, especialista en caligrafía y tipografía, de larga trayectoria profesional en comunicación gráfica y dirección artística. En sus trabajos, tipografía y caligrafía actúan en la misma dirección que el dibujo de personajes concebido por Carlos Grangel y también desarrollado por Jordi Grangel, para definir un estilo acorde con cada relato cinematográfico.

Cierto es que en muchas películas no se reproducen los textos que han formado parte del proyecto, de ahí lo significativo de Corpse Bride (La novia cadáver, Tim Burton, 2005), un ejemplo donde las caligrafías se han incorporado al filme en el logotipo del título, créditos de apertura y carteles aclaratorios en medio de la misma (intertítulos), además del diseño de nombres para los personajes y la promoción comercial. Un caso que es paradigmático asimismo por la intervención de la caligrafía en el estilo gráfico de la película. Para ello, la caligrafía, a través de su lugar en la historia del diseño gráfico y la escritura, dialoga con las letras del pasado desde su posición contemporánea y en relación al relato cinematográfico.

\section{El estilo como poética visual}

Definir un estilo es necesario en proyectos de animación, pues no se trata solo de un conjunto reconocible de formas expresivas. El estilo, en general, ayuda a construir la connotación en diferentes planos del relato: el simbolismo que hay tras la historia contada, los espectadores previstos a los que está orientada una obra, la vinculación a géneros narrativos, los procesos técnicos, estética, utilidad social, etc. Tal como señala Norberto Chaves a propósito del diseño gráfico, la aportación del estilo a esos planos subraya su relación con el sujeto cultural ${ }^{4}$. Por su parte, Omar Calabrese hace notar que las formas expresivas se corresponden con efectos en el plano del contenido y el estilo se convierte en un conjunto de atributos de un actor social, sea un individuo, un grupo o una épocas. Por ello se suele decir que el estilo implica una concepción estética del medio y sus obras, "un modelo del universo" 6 .

En el caso que nos ocupa, donde los proyectos se refieren a películas diferentes con varias historias y directores, se hace necesario introducir otro modo de entender el estilo, señalado por Santos Zunzunegui: su consideración como identidad visual o poética visual de una obra. De este modo, se traslada el centro de interés desde el autor hacia la obra, como respuesta a algunos problemas observados en la concepción tradicional, y así concluir que "el estilo se confunde con el ser mismo de toda obra que se quiere artística"?.

Desde ese punto de vista, el estudio sobre caligrafía que se va a llevar a cabo aborda su participación en la poética visual que subyace a proyectos destinados al cine de animación. Una identidad visual cuya puesta en forma se alimenta de rasgos que a su vez pueden provenir de otras huellas estilísticas, en el sentido tradicional, de la época, las técnicas, el autor, etc. El estilo es atributo de la obra, recreada a través de la experiencia profesional y vital del individuo que le da forma; pero a la vez, es también una muestra del medio y la época a la que pertenece (zeitgeist), entendiendo aquí la época como el momento actual del proyecto, no de la historia que se cuenta. Cuando Grangel Studio desarrolla el diseño de personajes y textos, incorpora los estilemas gráficos propios de su bagaje profesional y del 
impulso emocional que se imprime al grafismo del dibujo como huella de autoría. Sin embargo, en cada caso, el estilo pertenece por derecho a la especificidad de cada relato. En consecuencia, la búsqueda que da paso a una inspiración plástica siempre comienza por acercarse a conocer el asunto motivador, el argumento del filme, su ambientación, personajes, referencias literarias 0 artísticas. Tal como han explicado en diversas ocasiones Carlos Grangel, Jordi Grangel y Carles Burgès, si la película está protagonizada por animales, se estudia su comportamiento y anatomía en directo o a través de documentales. Si es de época, se recopila documentación histórica o se visitan los museos y lugares relacionados con el tiempo y lugar del relato, etc. Todo ello sin olvidar que la orientación del director de la película es fundamental, sobre todo si su cine es tan personal como el de Tim Burton, que eligió a Carlos Grangel para los dibujos de Corpse Bride porque había visto un trabajo suyo anterior con un estilo acorde al que buscaba para esa historia. Así, Burton debió ver en el estilo Grangel confluencias y semejanzas con su propio estilo, por lo que no extraña, en reciprocidad, que algunos de los personajes puedan recordar otras criaturas de su filmografías.

\section{El gesto del trazo en el estilo caligráfico}

Tal como afirma Meyer Schapiro, la descripción de un estilo suele hacer referencia, sobre todo, a los rasgos formales, aunque estos no sean suficientes para su caracterización completa9. Es sabido, por otra parte, que los rasgos formales no solo se refieren a la forma, pero esta es fundamental en la expresividad del dibujo y la caligrafía. Así, las particularidades de la forma en el dibujo figurativo derivan de cómo se aplican transformaciones gráficas a partir de un modelo real o imaginario, y la repercusión de su plástica en el plano del contenido tiene relación con el temperamento que la mano imprime al trazo. Esa huella del autor, de forma intuitiva o deliberada, genera operaciones geométricas, analíticas, ópticas, cinéticas, que transforman el referente para dar lugar a formas individualizadas, observables a través de los parámetros de dimensión, posición y orientación ${ }^{10}$.
El estilo de Grangel Studio, en palabras de sus miembros, es muy diferente del clásico modelo Disney:

- [C. Burgès]: El estilo Disney suele ser más dulce, más blando, aunque este aspecto también varía en función del argumento de las producciones.

- [C. Grangel]: Podríamos decir que nosotros empleamos formas más gráficas, más angulares. Tratamos de ofrecer un look diferente al de Disney. Nosotros reinventamos nuestro estilo y conseguimos que nuestros personajes no se parezcan entre ellos" ${ }^{11}$.

Observando sus dibujos, ya se intuye que la caligrafía es un procedimiento coherente con ese disegno de personajes más gestual, en cierto sentido de formas más primigenias y menos edulcoradas que las del dibujo animado clásico, de ahí que esa variante de escritura sea habitual en la elaboración de sus proyectos. La caligrafía es la escritura que más se acerca al dibujo en lo que concierne a la gestualidad del trazo directo; no lo es, en cambio, en lo referido al uso del retoque. A diferencia de tipografía y rotulación, la caligrafía se basa en el trazo simple (como lo denomina Noordzij) ${ }^{12}$, depende del utensilio y emplea para ello instrumentos similares a los del dibujo: cálamos, plumas, pinceles. Hay pues un vínculo primario entre ambas técnicas, reflejado en la etimología del término estilo, que proviene de stǐlus, la palabra latina que nombra al punzón para escribir, en definitiva, al instrumento gráfico y su consecuente aportación gestual al estilo en la manera de dibujar o escribir.

En el gesto del trazo, las transformaciones de la letra son comparables a las que el dibujo efectúa para dar forma a las figuras. Si el Groupe $\mu$ describe la dimensión, posición y orientación, como parámetros de la forma (que se complementan con textura y color) en el signo plástico ${ }^{13}$, por su parte, Claude Mediavilla, en su tratado sobre caligrafía, caracteriza la forma de un modo muy semejante, a través de los contornos, la dimensión, la posición, la dirección, el contraste y el color. Además, vincula la caligrafía con cierto tipo de pintura abstracta, considera que el poder emocional de las formas expresivas está relacionado

con la sensación íntima que tenemos de nosotros mismos $y$, por consiguiente, de nuestra energía 


\begin{abstract}
y actividad interiores [...] las formas nacen de la programación y el intercambio incesante entre nuestra actividad interior y el espacio exterior. [...] Cuando un calígrafo empieza su calentamiento ante la mesa de trabajo, activa energías y fuerzas que emanan de las distintas partes de su cuerpo: energía fisica, fuerza muscular del brazo y de la mano, etc. Por otra parte, su actividad interior proyecta sobre el papel su experiencia corporal, que a su vez da origen a las formas expresivas ${ }^{14}$.
\end{abstract}

Esta asociación forma-gesto sirve no solo para la abstracción pictórica. En el dibujo de personajes, incluso antes de adquirir movimiento en la película, el impulso de la mano hace de intermediario y fundamenta la estilización, para llegar más allá de la simple descripción de figuras, igual que la caligrafía va más allá del mero reconocimiento de palabras. En los trabajos de Burgès, el estilo caligráfico que sigue a la idiosincrasia de la película resulta una expresión indicial, volcada en el ritmo y orientación que marca el gesto personal del trazo. Gesto, como se ha apuntado antes, que tiene importancia en gran parte de las Bellas Artes, a través de su destreza y revelación emocional. De ahí que a la caligrafía y al dibujo de personajes se les pueda trasladar estas palabras de José Saborit dedicadas a las pinceladas en el arte de la pintura:

Lo que mejor habla del temperamento, del carácter de una pincelada, es el impulso que porta, el modo en que ha sido aplicada sobre el soporte, la presión, la manera en que se ha producido el contacto físico, el encuentro entre el pincel y el lienzo: si ha sido un encuentro breve y frontal, directo, sin arrastrarse o restregarse, o si por el contrario ha habido un desplazamiento sostenido e insistente, o de cualquiera de las infinitas formas en que dos cuerpos pueden tocarse [...]. La pintura habla por medio de la mano, es ella la que vierte el trazo, el extremo del cuerpo por donde salen y se exteriorizan flujos de energías ${ }^{15}$.

Ya los tratados del Settecento, recuerda J. María Ribagorda, relacionaban la belleza de la caligrafía y el arte de rasguear con el gesto.

Pues de eso se trata: de rasguear. El cerebro apenas tiene tiempo de dar órdenes (ductus) cuando se escribe en libertad y prima lo gestual, la caligrafía encuentra así su razón de ser, su expresión más auténtica' ${ }^{16}$.
En consecuencia, la caligrafía asume un papel más allá de la escritura personal (o escritura epistolar), con la que sin embargo comparte su fundamento en el recorrido natural de la mano a través del ductus; teniendo en cuenta que el "ductus no consiste simplemente en descomponer el signo en cierto número de trazos, sino también en precisar el orden en el que estos están trazados y su sentido con respecto al instrumento de escritura" ${ }^{17}$. Ahora bien, teniendo ese origen común en el que se hace patente la huella personal, la caligrafía destaca de la escritura epistolar por la aspiración de conseguir una bella escritura, a través de una "ejecución especialmente cuidada" ${ }^{18}$. Se asocia pues con belleza, arte, técnica y dominio de los principios fundamentales de la escritura ${ }^{19}$. Una búsqueda estética que, con frecuencia, ha llevado a este modo de escribir en dirección al ornamento, ligado al movimiento de la mano y al instrumento que porta; pero también, sobre todo en su desarrollo contemporáneo, a la gráfica estilizada usual en el plano expresivo del dibujo o la pintura.

Los diseños de Burgès para proyectos de animación no se acaban en la caligrafía, aunque sea lo significativo de este estudio, pues también hay, por separado o en mixtura, rotulación y tipografía. A tal efecto, es útil la diferenciación que hace Noordzij de dichos procedimientos de escritura: mientras que la caligrafía proviene del gesto directo de la mano (trazo simple), en el caso de la rotulación "las formas son más adaptables que en la escritura a mano, ya que admiten trazos de retoque" ${ }^{\prime 2}$; por su parte, la fuente tipográfica permite a cualquiera escribir con caracteres antes diseñados. Dado ese matiz parece oportuno recordar que la rotulación (lettering) en muchos aspectos tiene más de dibujo que la caligrafía, ya que consiste en dibujar letras, incluso con ejemplos de interpenetración entre esas letras o palabras con imágenes figurativas. Pero no es esa la confluencia que trata este artículo, sino la que se da en la significación del gesto asociado a los parámetros de la forma en el signo plástico.

Es fácil suponer, no obstante, que muchas situaciones implican la colaboración de los tres modos de escritura: la caligrafía puede tornarse rotulación si se retoca; la tipografía se puede construir o imitar desde el gesto caligráfico; la rotulación 
puede dar paso a una fuente tipográfica, etc. En los trabajos de Burgès en Grangel Studio, el dibujo del texto se suele elaborar como caligrafía o a veces como rotulación, incluso en aquellos casos en los que hay implicada una fuente tipográfica anterior. Por ejemplo, la escritura caligráfica predomina en logotipos para proyectos de películas como Cats (1991), Balto (1995), Spirit: Stallion of the Cimarron (2002), Sinbad: Legend of the Seven Seas (2003), Hotel Transylvania (2012) o Corpse Bride (2005). También en la mayoría de nombres diseñados para los personajes de esas películas. La rotulación se aprecia en proyectos de diseño para los títulos de The Fearless Four (1997), Antz (1998), Shark Tale (2004), Madagascar (2005), Flushed Away (2006) o, ya cerca de lo tipográfico, en How to Train Your Dragon (2010). En cuanto a las propuestas con una inspiración más tipográfica, generalmente transformada por el dibujo para individualizar el logotipo, se pueden mencionar los títulos para The Prince of Egypt (1998), El Dorado (2000), The Pirates! In an Adventure with Scientists! (2012) y, sobre todo, ya fuera del cine de animación en el logotipo de Gladiator (2000). El uso de estos tres procedimientos de escritura se extiende, como es lógico, a las diferentes denominaciones secundarias de los proyectos presentados para cada película, en especial los logotipos para personajes.

\section{Principios que orientan el estilo caligrá- fico en Grangel Studio}

En lo que a este estudio atañe, el ímpetu del gesto caligráfico es el centro del estilo desarrollado por Carles Burgès para proyectos de animación. No obstante, junto a esa fuerza significante propia de la caligrafía contemporánea, hay principios que orientan su estilo, imbricados en una mixtura variable que conviene concretar.

- Coherencia y empatía de la caligrafía con el relato cinematográfico, teniendo en cuenta: el carácter de los personajes, si son valientes, dulces, inquietos o malvados; la época y lugar en los que se sitúa la historia y sus imágenes, sea la arquitectura del Antiguo Egipto, los paisajes del salvaje western o los vestidos de la Inglaterra victoriana; su cercanía a géneros cinematográficos o literarios, de aventuras, comedia, melodrama; el tono emocional, humorístico, melancólico, gótico; el ritmo de la narración; si el público hipotético es infantil o abarca diversas edades; etc.

- Consonancia con el estilo global que Grangel Studio desarrolla para una película a través del dibujo. Esta isotopía se aprecia con frecuencia en una similitud de la plástica de la letra con la plástica del dibujo del personaje al que representa, teniendo en cuenta que el estilo de las figuras también tiene como objetivo fundamental la interpretación coherente del relato.

- Cualidades estéticas y expresivas de la letra por su configuración abstracta, por sus posibilidades como signo plástico, referidas al modo en que interpretamos las variaciones de los parámetros de la forma: dimensión, posición y orientación. La atribución de significados a esas variaciones es débil, ambigua, difícil de verbalizar, pero importante para el dibujo y también para la caligrafía y tipografía. Este punto tiene relación con las analogías formales del texto y el dibujo de personajes que se mencionan en el punto anterior.

- Por último, recordar que la propuesta caligráfica de Burgès no solo tiene una factura rotunda de gran expresividad y talento plástico, sino que además contiene el conocimiento de la herencia caligráfica del pasado. Los diferentes alfabetos históricos se interiorizan como materiales básicos para dar cuerpo a creaciones con estilo propio. En algunos casos, ello supone la inspiración en modelos de otra época, buscando la empatía con las características de la historia o los personajes correspondientes.

Se repasan a continuación algunos ejemplos en los que la interacción de estos factores sigue un camino donde el estilo de la escritura se ha hecho con los años cada vez más expresivo en el trazo personal, de acuerdo a una concepción contemporánea de la caligrafía que observa y recrea los procedimientos históricos. Así en Corpse Bride y Hotel Transylvania se aprecia la interpretación de escrituras prerrenacentistas (góticas o medievales) desde el gestualismo contemporáneo. Sus grafías están más cerca del expresionismo que del virtuosismo del Settecento, donde abundaban florituras y arabescos. Tampoco hay parecido con la escritura común caligráfica de pluma puntiaguda que se impulsó en esos años de 1700 a 1800, conocida como letra inglesa, 
modelo habitual para el aprendizaje de la escritura en los siglos siguientes ${ }^{21}$. Hay que repasar proyectos anteriores de Grangel Studio para encontrar ese tono de caligrafía clásica, en títulos como Balto (1995), en el nombre diseñado del perro Buster en The Fearless Four (1997) y diversos personajes del Jester Till (2003), en los que, no obstante, el trazo personal, a veces anguloso o al menos dotado de más expresividad, se va imponiendo a las formas ovaladas propias de la caligrafía inglesa.

La predilección por el tono gótico-expresionista de los logotipos para Corpse Bride y Hotel Transylvania está mediada por vínculos con el siglo XIX. En el primer caso, a través de la ubicación del relato y el cuento que lo inspira, y en el segundo, aun en su tono humorístico para niños, por la aparición de personajes decimonónicos de terror como Drácula o Frankenstein, teniendo en cuenta que dicho siglo se considera un paradigma de las narraciones románticas, góticas y fantásticas a través de autores como Bram Stoker, Mary Shelley o Robert Louis Stevenson. También es la época de los cuentos populares recopilados por los hermanos Grimm, así como de una mirada al mundo medieval ensalzado por las teorías de John Ruskin, la pintura de sus seguidores prerrafaelitas o las ediciones de William Morris.

En Hotel Transylvania, una de las variaciones del título muestra el estilo principal del proyecto gráfico (fig. 1). El ritmo del pincel decidido y enérgico parece, sin embargo, efectuado con un movimiento reposado de la mano, que hace notoria la consistencia de tinta líquida caída sobre papel, como caen en una pared las chorreaduras de sangre en películas de terror o el dripping pictórico sobre el lienzo; si bien aquí la pincelada está controlada, dirigida. El resultado es una forma imprecisa en los contornos, similar a algunas tipografías grunge de la década de 1990 (fig. 8H). La cadencia del trazo permite que las letras se alarguen hacia abajo (como las agrestes esculturas de Giacometti lo hacen hacia arriba) y formen un extremo puntiagudo, pero con el límite a veces suavizado, roto por los caprichosos recorridos de la tinta. Esta continuación, realizada con el pictoricismo expresionista del pincel, recuerda los trazos descendentes que prolongan de forma creativa algunas letras en la escritura

\section{HOTEL TRANSILNNIA}

Fig. 1. Idea para el título de producción de Hotel Transylvania (2012). Caligrafía de Carles Burgès / Grangel Studio. (C) Sony Animation

gótica, incluidas algunas creaciones del siglo XIX, como Fette Fraktur (figs. 8B y C). Merece la pena observar en esta tipografía, diseñada por Johann Christian Bauer en 1850, el fuste de la efe, más grueso de lo habitual en las góticas antiguas, prolongado por debajo de la línea base, como un descendente cada vez más afilado. Dado que además no tiene un remate inferior horizontal (igual que otros glifos góticos), ${ }^{22}$ el resultado es su característica forma acuchillada. De hecho, esa clase de alargamientos agudos se puede encontrar no solo en muchas letras góticas, sino también en ejemplos más antiguos, como la semiuncial recreada por el escriba en algunas páginas del mismísimo libro de Kells, hacia el año 800. Los parecidos con algunas letras góticas, en definitiva, no se refieren a la estructura de la letra en conjunto, pues el logotipo está en mayúsculas, sino a algunos detalles de esa estructura, junto a la forma y gesto en el acabado de ciertos trazos.

La orientación estilística del logotipo de Hotel Transy/vania se repite con libertad de gesto y personalización para los nombres de la mayoría de personajes del filme (fig. 2), dejando jugar al pincel para que la inspiración expresionista se vuelva por igual humorística, como se puede apreciar en las locas elongaciones del trazo en los espacios intermedios del logotipo para Gustav, que acaban en pequeñas espirales; pues el contrapunto del humor está presente en todos los aspectos del estilo aportado por Grangel Studio a dibujos y textos. En según qué personajes, la imagen del nombre se aleja más o menos del estilo general definido por la gráfica del título, hasta el caso extremo de las letras coloreadas para Blob and Blobette, hiperbólicamente redondeadas; por tanto, blandas, amistosas y divertidas como sus cuerpos compuestos de anillos gelatinosos. Los nombres de la familia del hombre lobo se escriben con le- 

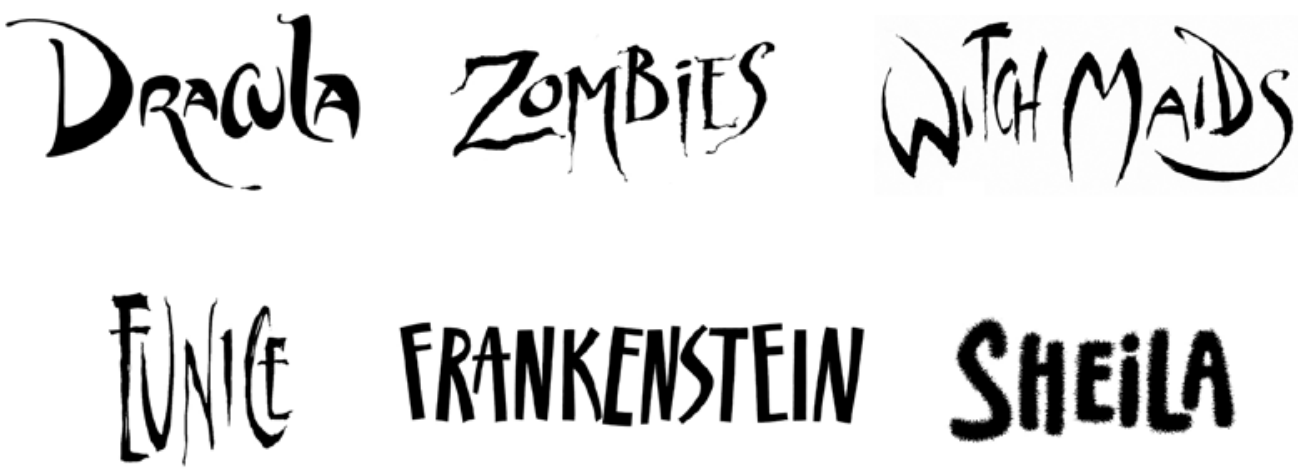

\section{FRANKENSTEIN}
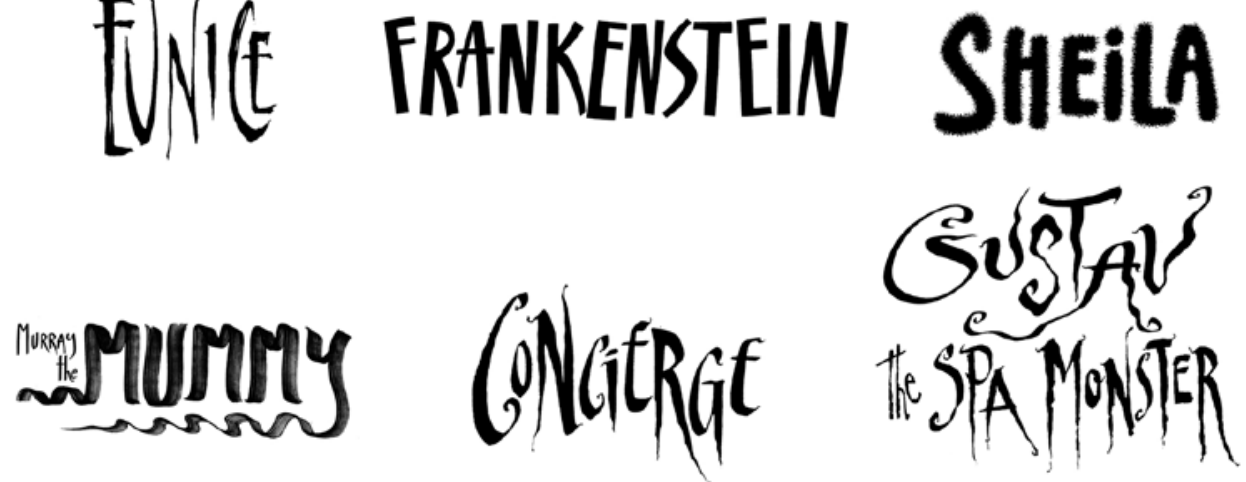

(C) Sony Animation

Fig. 2. Logotipos para los personajes de Hotel Transylvania (2012). Caligrafías de Carles Burgès / Grangel Studio. (C) Sony Animation

tras cubiertas de pelo, como un abrigo que cubre su esqueleto tipográfico. Para Frankenstein hay letras grandes, verticales y algo rígidas, propias de un personaje bonachón y lento de reflejos. La momia de Hotel Transylvania, Murray, como todas las momias del mundo va perdiendo sus ajadas vendas, y su logotipo pincelado en plano, se desenrolla como ellas cuando forma la palabra Mummy. Así, las letras inicial y final en forma de onda parecen caer tras la palabra como los extremos sueltos de la venda, para crear un adorno que sirve de subrayado al texto. Dada la película de que se trata, no se puede obviar el ductus para el logotipo de Drácula, que destaca en intensidad contenida sobre los otros, mucho más vigoroso, autoritario y elegante, con hábiles giros de pincel, como los vuelos del murciélago, y con toda la personalidad del líder de los monstruos. Su letra inicial, la $D$, recuerda el perfil de un torso fuerte y digno, tal como corresponde al aristocrático conde propietario del Hotel Transylvania.

Muchos otros personajes de Grangel Studio tienen expresiones comunes en el dibujo y su nombre diseñado. Por el momento, merece la pena recordar un ejemplo en el que el significado que transmiten las formas de la palabra trabaja con elegancia y sencillez en la misma dirección que el estilo del dibujo y el temperamento del relato. Se trata de una de las propuestas para Spirit: Stallion of the Cimarron (2002) (fig. 3). Los trazos de este logotipo, desde el punto de vista de la semántica plástica, son directos, limpios, veloces y suaves. Esta semántica primaria de la forma concuerda con el carácter decidido y valiente atribuido al protagonista, El corcel indomable, tal como se subtituló en español. Un animal salvaje que, atrapado por soldados norteamericanos, lucha incansable por su libertad, en un filme donde destacan las vivencias y sentimientos de caballos mustang humanizados por el dibujo de Carlos Grangel. Si se detiene la mirada en el logotipo, tanto los trazos rectos como los cambios de orientación se aprecian vigorosos y la vez suaves, ligeros, como buscando la ingravidez espiritual, síntoma de la nobleza sin requiebros que apunta el estilo creado para Spirit. También en los extremos pincelados de la letra es posible observar una forma semejante a las crines blancas 


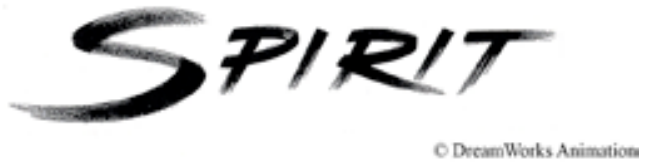

Fig. 3. Idea para el título de producción de Spirit: Stallion of the Cimarron (2002). Caligrafía de Carles Burgès / Grangel Studio. (C) DreamWorks Animation

que, mecidas por el viento, se nos antojan la mejor imagen de ese corcel noble y salvaje, viviendo en libre armonía con la Naturaleza.

\section{La expresividad neogótica en Corpse Bride}

Conocida en España como La novia cadáver (Tim Burton, 2005), Corpse Bride es uno de los proyectos más amplios de Grangel Studio, también desde el punto de vista tipográfico. El trabajo incluyó el desarrollo visual del título (un logotipo caligráfico gestual, cercano a la ilustración), los créditos de apertura, los intertítulos y el diseño para los nombres de personajes. Todo ello implementado, según casos, en la película o en las promociones comerciales asociadas a ella.

La pieza principal de este conjunto es el logotipo del título (fig. 4), que aparece en el comienzo del filme, tras la imagen del protagonista escribiendo sobre la calidez de un papel ligeramente arrugado. Inicialmente, se observa de cerca el discurrir de la pluma y la suave determinación del trazo, pero lo que en el detalle sugiere un ornamento de texto, variada la distancia muestra el dibujo de una mariposa, cuyo modelo vivo está retenido en una campana de cristal. El momento en el que Victor libera a la mariposa es el clímax de esta apertura y coincide con la presentación de la marca gráfica Corpse Bride, en letra blanca, iluminando la pantalla sobre la imagen en movimiento. Después, la mariposa y su etéreo color azul volarán sobre las calles grises del pequeño pueblo gris de inspiración victoriana en el que se desarrolla la historia. Transcurso en el que también se sucede el reparto de actores de doblaje y los responsables de la película, con una caligrafía diseñada ad hoc por Burgès, ya convertida en fuente tipográfica.

Este arranque en el que interviene la expresión caligráfica del título sirve para adentrar al espectador en el universo del relato y la poética

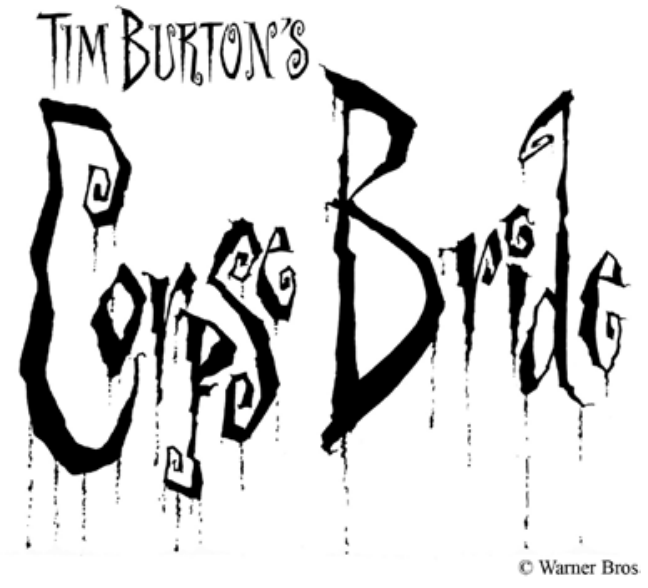

Fig. 4. Título final para Corpse Bride (2005). Caligrafía a tinta y pincel de Carles Burgès / Grangel Studio. (C) Warner Bros.

cinematográfica del director, lo que constituye un principio funcional clave para las imágenes de apertura en una película. Al mismo tiempo, semejante logotipo expone con claridad la concurrencia gestual entre dibujo y caligrafía, unión reforzada por algunos detalles, como los pequeños trazos intermitentes que se descuelgan de las letras a modo de raíces del texto. En la versión definitiva del filme se suaviza esta relación para priorizar la lectura del título sobre la escena de arranque, pero en otras variaciones es más evidente la referencia a esas raíces entrelazadas que salen de la tierra para alcanzar los caracteres escritos: un símbolo de lo que ocurre en el momento detonante de la historia, cuando Victor vaga por el bosque tras su fracaso al pronunciar los votos en el ensayo de la boda. Desesperado, los recita de nuevo una y otra vez hasta hacerlo correctamente y poder, entonces sí, colocar su anillo alrededor de una raíz que parece un dedo. De repente, esta resulta ser la mano de quien, en consecuencia, ya es su mujer, la bella novia cadáver que le arrastra hacia el inframundo de los muertos, unos seres sorprendentemente cromáticos y divertidos. La rima entre la forma del logotipo y las ramas y raíces que dan lugar al nudo central del relato está resuelta con destreza en la aplicación cadenciosa del trazo, con detenciones, quiebros y temblores gráficos provocados, que comparten el estilo del dibujo en la película, incluso en su movimiento, además de algunas semejanzas concretas no solo con elementos del 
paisaje, sino también de los personajes: la diadema de la novia, los pelos de la señora Plum o la perilla del anciano Gutknecht.

El trazo quebrado, repetido en algunos detalles del dibujo, es habitual en la mayoría de logotipos para los personajes, con un estilo de expresividad contemporánea e instintiva que no se somete a los modelos caligráficos escolares. Ejemplo de ello son las letras del alfabeto desarrollado en minúsculas para la pre-producción, nombre de personajes y promoción comercial (fig. 5). Sus glifos tienen una factura gráfica primigenia y mirarlos permite imaginar un alfabeto construido gestualmente, con útiles primitivos, antes de la consolidación medieval de las minúsculas latinas. Cada logotipo se adecúa, sin embargo, a las peculiaridades de la criatura que nombra, de su carácter y sobre todo de su dibujo, como se ha mencionado para la generalidad de proyectos. Con objeto de no abundar en un exceso de ejemplos, solo detallaremos ahora los casos de Victor y Victoria: la pareja protagonista (junto a Emily, la novia cadáver), que simboliza la unión idílica de enamorados, turbada por la trama del filme (fig. 6). Ambos comparten el estilo habitual de toda la producción, pero aquí el trazo es menos quebrado, los zigzagueos del pincel han cedido a un gesto más limpio y directo, semejante al carácter abierto y la inocencia de sus portadores. No obstante, la armonía de sus dibujos no excluye una necesaria complementariedad que también se traslada a los nombres. El trazo para Victor es más vertical y enérgico, de ahí que la huella del pincel deje rastro, no sea del todo opaca; en cambio la forma de las letras para Victoria es más redonda y sensible, la huella no está marcada, el ritmo parece más reposado y en conjunto resulta de una cierta feminidad victoriana. De acuerdo a esa feminidad, las modulaciones de los glifos presentan aquí más contraste entre partes del trazo muy finas y otras mucho más gruesas, favoreciendo cierta elegancia ornamental que recuerda de lejos, en una concepción diferente, la modulación de las letras didonas de finales del siglo XVIII, tan habituales estas los siglos posteriores en usos vinculados al mundo de las revistas de moda. Para completar esa idea, en el nombre de Victoria los remates en espiral, que también se dan en otras denominaciones para la película, se recrean con repetición y sentido lúdico del adorno. Un tipo de

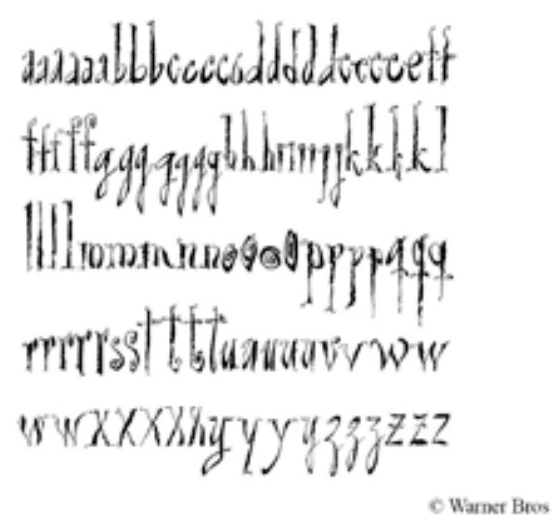

Fig. 5. Alfabeto de pre-producción para los nombres de personajes y promoción comercial de Corpse Bride (2005). Caligrafías de Carles Burgès / Grangel Studio. (c) Warner Bros.

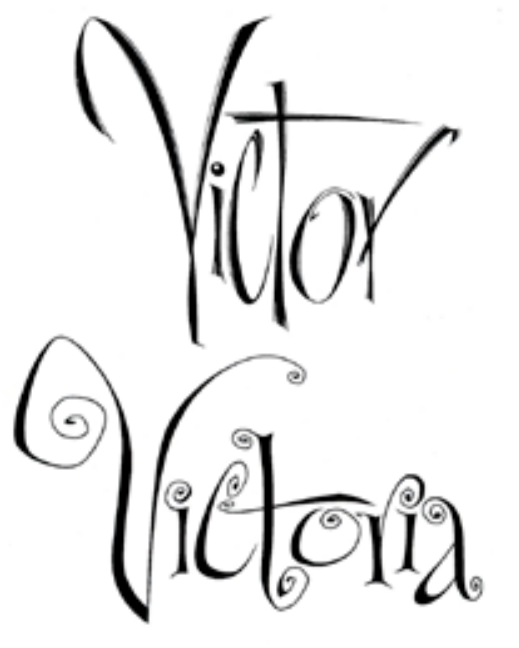

( Warner Bros

Fig. 6. Caligrafías para los personajes Victor y Victoria, Carles Burgès / Grangel Studio. (c) Warner Bros.

ornato que es posible encontrar con frecuencia en tipografías victorianas, como Ringlet, de Herman Ihlenburg (1882) (fig. 8D).

La historia de Corpse Bride, ambientada precisamente en la época victoriana, es una adaptación de un cuento ruso-judío del siglo XIX, a su vez inspirado en otro del siglo XVI escrito por el místico Rabbi Isaac Luria de Safed. En el original no había una difunta, sino un demonio: hasta 
la versión decimonónica no aparecería la mujer asesinada en el día de su boda y enterrada con su vestido de novia. A partir de ahí, Tim Burton se aleja del terror habitual en muchos cuentos populares, pues con un planteamiento habitual de algunas películas suyas, se subvierte la dicotomía entre el mundo de los vivos y el mundo de los muertos, que deja de ser anticipo de terror y oscuridad para mostrarse con atractivas cualidades (frente al mundo de los vivos), reflejadas en su cromatismo y sus canciones, donde "la muerte vuelve a ser más divertida que la vida" 23 . El humor es así un adecuado contrapunto para transformar el miedo a la muerte a través de la estética, tal como señala Encarna Ramiro sobre Corpse Bride ${ }^{24}$. Un argumento que relaciona con estas palabras de Eugenio Trías sobre el cine comercial actual:

La transformación del dolor en placer se produce así por intercesión de lo cómico: único modo acaso que tiene el arte por configurar estéticamente ese límite señalado por Kant; ese límite del arte ( $y$, como veremos, también condición) que es el asco, en tanto el asco constituye una de las especies de lo siniestro25.

Humor y belleza, instrumentos transformadores de lo siniestro, impregnan también el ductus de la letra basado en un trazo quebrado y tembloroso del logotipo Corpse Bride y del resto de caligrafías, con el sutil y lúdico zigzagueo en el movimiento de la mano, pues el temblor es un síntoma característico del miedo y los ataques de pánico. Se tiembla de miedo. Pero también de risa. Por ello, el humor de la película, se recoge caligráficamente con cierta suavidad en el temblor del pincel, el instrumento elegido por Burgès en este caso, menos cortante que la pluma o el cálamo, para un temblor de miedo destensado, flojo, divertido, parodia de sí mismo.

La consonancia visual de las letras con el espíritu del relato se refuerza a través del conocimiento de la Historia de la escritura y su recreación práctica en una poética que revisa la tradición desde la contemporaneidad. Este logotipo, más incluso que el posterior de Hotel Transylvania, comparte rasgos de estilo con las letras góticas, sobre todo por su angulosidad y curvas quebradas, los elementos más característicos de la escritura gótica ${ }^{26}$, frente a otras caligrafías como

\section{ABCDETGII Ј K LMNOPQ hรTUVWXYZ 1234567890

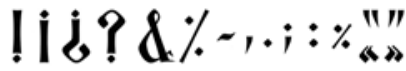

o Wamer Bros

Fig. 7. Alfabeto final para los créditos de apertura de Corpse Bride (2005), Carles Burgès / Grangel Studio. (C) Warner Bros.

la letra inglesa, que se construye "sobre la base de un óvalo dos veces más alto que ancho" ${ }^{27}$. Esto es posible apreciarlo, por ejemplo, en la "o" del logotipo (fig. 4) comparada con los glifos del mismo carácter en las cuatro familias góticas principales, textura, fractura, bastarda y rotunda (fig. 8A). También es propio de la letra gótica el ductus geométrico que marca los tiempos del desplazamiento del trazo, resultando de ello su angulosidad, visible por igual en las caligrafías para los créditos de apertura en la película (fig. 7 y figs. 8A, B, C y F).

Conviene recordar que la letra gótica, junto al resto de escrituras medievales, es también caligráfica en su origen. Todas ellas, en los siglos anteriores a la imprenta sirvieron para dar cuerpo a los textos manuscritos y en particular a los códices, precedentes de los actuales libros; por ello, siendo caligráficas, dieron un paso claro hacia la letra tipográfica, a su presencia sistematizada como unidad modular móvil. Pero las caligrafías de Corpse Bride no son versiones de tipografía gótica, lo que sí ocurría en otras realizadas para The Adventures of Don Quixote and Sancho (1993), The Emperor's new Clothes (2002) y The Three Musketeers (2008). La evocación viene, sobre todo, a través de la angulosidad del trazo y el grosor de las letras, ya que la tipografía gótica, debido a su particular técnica caligráfica, es gruesa, como los estilos bold (de ahí su denominación inglesa, Blackletter). Pero el instrumento cambia, no es la pluma biselada sino el pincel y no coinciden el número de trazos y orientación del ductus; tampoco el esqueleto de las letras que, sobre todo en el logotipo, es 


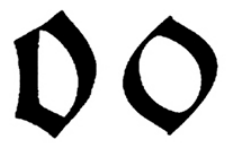

A.

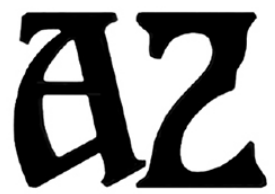

E.

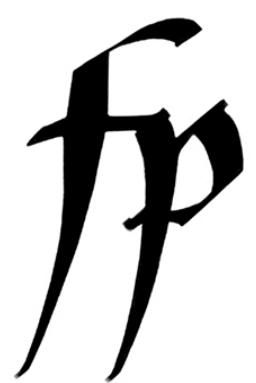

B.

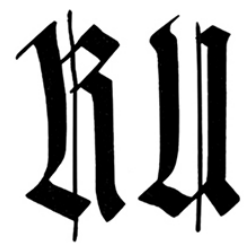

F.

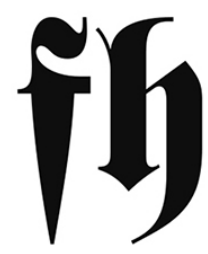

C.

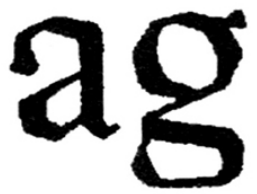

G.

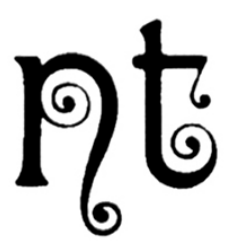

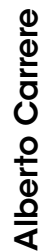

Fig. 8. Diversas tipografías. A. Dos oes góticas, de fractura y bastarda. B. Cursiva gótica del siglo XV. C. Fette Fraktur (J. Christian Bauer, 1850). D. Tipografía victoriana Ringlet (Herman Ihlenburg, 1882). E. Letras bajo la influencia del movimiento Arts \& Crafts y del art nouveau, hacia 1894. F. Estudio de gótica de textura (Rudolf Koch, 1924). G. Tipografía expresionista Preissig (Vojtěch Preissig, 1924). H. Tipografía grunge President Nixon (Pete McCracken, hacia 1990)

una recreación caligráfica contemporánea, por su cercanía al dibujo, su interés en la investigación de soportes e instrumentos y la exploración subjetiva del gesto abstracto.

En cuanto a los créditos de apertura, se trata de letras mayúsculas, donde predomina también el trazo quebrado (fig. 7). En las pruebas caligráficas originales previas a su digitalización, el pincel trazaba recorridos incluso en zigzag, a veces más angulosos, a veces más suavizados, para reforzar la expresividad, junto a la sensibilidad lúdica y melancólica del proyecto. Sin embargo, el esqueleto de estas mayúsculas no se parece al habitual en las góticas, aunque tampoco recuerda a las letras capitales romanas que fundamentaron la cultura gráfica occidental. La sensación que producen evoca un primitivismo filtrado por el movimiento Arts \& Crafts que en plena época victoriana recuperó las formas unciales, carolinas, góticas..., con líneas orgánicas cercanas a la mirada art nouveau, a través de imprentas como Kelmscott, comprometidas en recuperar la belleza de los libros incunables ${ }^{28}$. Una mirada en detalle de ese alfabeto (fig. 7) muestra dos rasgos muy habituales en tipografías del modernismo decimonónico (fig. 8E): la asimetría de mayúsculas habitualmente simétricas ( $A, M$, W, V), por el desvío en curva orgánica de uno de sus trazos laterales; y la posición del travesaño de letras como A, E, F o H, más alto de lo habitual, muy cerca de la línea de altura de las mayúsculas, con el resultado, por ejemplo, de un triángulo de contraforma interior extremadamente pequeño en la $A$, casi alcanzando el ápice. En relación a esos rasgos formales, hay que mencionar en particular las tipografías de Rudolf Koch, con sus originales interpretaciones de lo gótico y medieval, como Deutsche Schrift (1906-1921), calificada de expresionista por Bain y Shaw ${ }^{29}$, que incluye versiones estrechas, como los créditos aquí analizados (fig. 8F).

De lo afirmado hasta ahora, se entiende que tanto en el logotipo de Corpse Bride como en los créditos de apertura y en otras denominaciones 
para la película, hay una sintonía, más allá de la tipografía gótica stricto sensu, con ese gusto por lo gótico que atraviesa diferentes épocas, entre ellas de forma destacada el siglo XIX, su narrativa y su arte. Una cultura recogida por diferentes movimientos de la contemporaneidad postmoderna, a los que no es ajeno el cine de Tim Burton, director y artífice fundamental del estilo global del filme. Así, en la gráfica de la película se interpreta aquello que ha hecho de lo gótico no tanto una tipografía de época como una huella expresiva transversal en la historia de la cultura, y con ella en la historia de la escritura, que ha inspirado en tiempos tan distantes como los de John Ruskin, William Morris o los prerrafaelitas y los actuales de tribus urbanas neogóticas, rotulaciones para tatuajes, música heavy metal e incluso grupos de ideología neonazi.

La inspiración gótica tiene lugares de complicidad con el romanticismo y el expresionismo, todos ellos afines al exceso emocional y los mitos de la muerte, todos ellos de presencia destacable en Alemania, país donde nacieron y vivieron los hermanos Grimm en el siglo XIX; época también de la Inglaterra victoriana en la que se sitúa Corpse Bride, así como del cuento ruso en el que se inspira. Los Grimm estudiaron las narraciones populares germanófonas y recopilaron sus cuentos de hadas (Kinder- und Hausmärchen, 1812-1815), editados, por cierto, en letra gótica, una escritura a la que se ha atribuido reiteradamente vínculos con la identidad nacional germánica ${ }^{30}$. En relación al expresionismo, ese temblor de lo quebrado que se aprecia en las caligrafías de Burgès ha sido señalado por Robert Bringhurst como característico de la tipografía expresionista ${ }^{31}$, a la que compara con el arte de algunos pintores, en concreto Oskar Kokoschka o Vincent van Gogh, a propósito de trazos que muestran con rudeza la huella de los materiales o una tosquedad angular alejada de modulaciones líricas: su ejemplo es la letra Preissig (Vojtěch Preissig, 1924) (fig. 8G). En el caso de los alfabetos de esta película hay un delicado equilibrio entre un trazo angular matizado con precisión y gestualidad, que puede hacernos recordar también, en sintonía con las tesis de Mediavilla, vínculos de la caligrafía contemporánea con otro expresionismo de mediados del siglo XX, en este caso abstracto, como abstracta es la letra en su esencia plástica.
La posición contraria al racionalismo clásico, propia del estilo cinematográfico de Tim Burton32, es un principio poético romántico que también puede explicar la confluencia de rasgos formales asociados a caligrafías de inspiración gótico-expresionista. Incluso sirve para orientar el camino hacia otra última referencia tipográfica, situada en la reacción postmoderna de tendencias que rechazaron el racionalismo funcional impulsado por el diseño suizo de mediados del siglo XX y todas las normas que regían los usos gráficos hasta entonces. En concreto, se pueden encontrar rasgos formales comunes con las tipografías grunge herederas del deconstruccionismo gráfico y el punk, hacia 1990, como President Nixon de Pete McCracken (fig. 8H), con expresionistas contornos fragmentados y letras deterioradas en las que parecen faltar trozos, algo similar a lo que ocurre en la irregular estructura del logotipo de Corpse Bride y en su "desintegración" orgánica hacia las raíces que surgen del inframundo.

\section{Conclusiones}

La participación de la caligrafía en los estilos gráficos para el cine de animación tiene una vía específica en los vínculos entre esta forma de escritura y el dibujo, centrados en el gesto y sus posibilidades significantes sobre el parámetro plástico de la forma. Una confluencia expresiva compatible con las posibilidades funcionales de un alfabeto tipográfico. De hecho, los principios que orientan su contribución en diferentes proyectos son aplicables por igual a tipografía y rotulación. En ese sentido, la forma que adopta el texto está conforme con el estilo gráfico de los personajes, a partir de las características y contexto del relato, e igualmente con la idiosincrasia cinematográfica asociada a la huella del director, que en el caso de Corpse Bride tiene unas formas expresivas muy definidas, situadas en el género fantástico y la tradición gótico-expresionista, matizadas por el humor y no exentas de melancolía.

En cuanto al gesto caligráfico y sus raíces históricas, el ejemplo estudiado no tiene una estética relacionada con modelos de virtuosismo ornamental clásico, sino con un sentido contemporáneo de la expresividad del gesto y la semántica de la forma. La presencia recreada de rasgos cercanos a letras prerrenacentistas, coherentes 
con el estilo gráfico de relato y personajes, incluye la revisión decimonónica de la época victoriana, el art nouveau y el movimiento Arts \& Crafts, así como aportaciones contemporáneas de estilos tipográficos expresionistas y postmodernos. Todo ello matizado desde trabajos vinculados a películas de animación, que requieren una sensibilidad particular en muchos casos teñida de sentido del humor y destinadas al público infantil o, mejor dicho, para todos los públicos. 


\section{NOTAS}

1 G. Vasari, Vite de'più eccellenti pittori, scultori e architetti, vol. I, Roma, Niccolo e Marco Pagliarini, 1550/1759, XV [consulta: 09/04/2016], https:// books.google.es/books? id=ptFMKV20 MQsC\&printsec $=$ frontcover $\&$ hl=es\&sou $r c e=g b s \_g e \_s u m m a r y \_r \& c a d=0 \# v=o n e$ page $\& q \& f=$ false.

${ }^{2}$ W. Tatarkiewicz, Historia de la estética, tomo III, Akal, Madrid, 2004, p. 40.

${ }^{3}$ La distinción entre signo icónico (asociado al reconocimiento figurativo) y signo plástico (asociado a formas, colores y texturas como tales), ha sido ampliamente debatida en semiótica visual. Esta formulación se encuentra con diversa terminología, en Hubert Damisch, Jean-Marie Floch, Göran Sonesson, etc. Véase, por ejemplo, Groupe $\mu$, Tratado del signo visual, Cátedra, Madrid, 1993. En relación a la pintura, véase $A$. Carrere y J. Saborit, Retórica de la pintura, Cátedra, Madrid, 2000.

${ }^{4}$ N. Chaves, "Regla, estilo y época. El dilema de los referentes del diseño en una época "sin estilo»", Temes de Disseny, $\mathrm{n}^{\circ}$ 19, 2002, p. 111 [consulta: 12/04/2016], http:// www.raco.cat/index.php/Temes/article/ view/29731/82927

${ }^{5}$ O. Calabrese, Cómo se lee una obra de arte, Cátedra, Madrid, 1993, p. 17.

${ }^{6}$ Groupe $\mu$, op. cit., p. 332.

${ }^{7} \mathrm{~S}$. Zunzunegui, Paisajes de la forma, Cátedra, Madrid, 1994, p. 81.

${ }^{8}$ Sobre el parecido de algunas criaturas de Corpse Bride con otras anteriores de la filmografía de Burton, véase M. Marcos Arza, Tim Burton, Cátedra, Madrid, 2007, p. 285.
${ }^{9}$ M. Schapiro, Estilo, artista y sociedad. Teoría y filosofía del arte, Tecnos, Madrid, 1999, p. 74

${ }^{10}$ Sobre el sistema de las transformaciones y los parámetros de la forma, véase Groupe $\mu$, op. cit.

11 "Entrevista: Grangel Studio, el éxito de la creatividad", Licencias de actualidad, $\mathrm{n}^{\circ} 27, \mathrm{pp} .66-70$ [consulta: 02/02/2016], http://licencias.com/ docs/ PDFs/27 grangel_118.pdf.

${ }^{12} \mathrm{G}$. Noordzij, El trazo. Teoría de la escritura, Campgràfic,Valencia, 2009, p. 9.

${ }^{13}$ Groupe $\mu$, op. cit., p. 191.

${ }^{14}$ C. Mediavilla, Caligrafía. Del signo caligráfico a la pintura abstracta, Campgràfic, Valencia, 2005, pp. 280281.

${ }^{15} \mathrm{~J}$. Saborit, Lo que la pintura da, Valencia, Pre-textos, 2018, pp. 162164.

${ }^{16} \mathrm{~J}$. M. Ribagorda y otros, Caligrafía española. El arte de escribir, Biblioteca Nacional de España, Madrid, 2015, p. 36.

${ }^{17}$ C. Mediavilla, op. cit., p. 5.

${ }^{18}$ F. Navarro Moragas, "Las formas artísticas de la tipografía y la caligrafía como vehículo histórico de expresión del zeitgeist", Laboratorio de arte, $n^{\circ} 26,2014$, p. 351 [consulta: 21/01/2016], http://institucional.us.es/ revistas/arte/26/articulo_17.pdf.

$19 \mathrm{~J}$. L. Martín Montesinos, "De la caligrafía a la tipografía", en R. Pelta, J. L. Martín Montesinos y M. Mas Hortuna, Ricardo Rousselot. ¡La caligrafía vive! Diputació de València, 2014, p. 34.

${ }^{20} \mathrm{G}$. Noordzij, op. cit., p. 9 y ss.

${ }^{21}$ Sobre la letra inglesa en la historia de la escritura, véase H. E. Meier, La evolución de la letra, Campgràfic, Valencia, 2011, p. 55.

${ }^{22} \mathrm{El}$ término glifo se refiere a una representación gráfica concreta de cualquier carácter tipográfico. En consecuencia, el glifo de una letra en una tipografía es diferente del glifo de la misma letra en otra tipografía.

${ }^{23}$ M. Marcos Arza, op. cit., p. 289.

${ }^{24} \mathrm{E}$. Ramiro, "Cuando ella es el monstruo. La novia cadáver de Tim Burton", Fòrum de recerca, $n^{\circ} 13$, p. 9 [consulta: 16/02/2016], http:// repositori.uji.es/xmlui/bitstream/ handle/10234/78528/forum_2007_45. pdf? sequence $=1$.

${ }^{25} \mathrm{E}$. Trías, Lo bello y lo siniestro, Barcelona, Ariel, 2001, p. 24.

${ }^{26}$ Sobre estas características de la letra gótica, véase, por ejemplo: R. Bringhurst, Los elementos del estilo tipográfico, 2a ed., Fondo de Cultura Económica, México, 2014, p. 324; también J. Pohlen, Fuente de letras, Taschen, Köln, 2011, p. 71.

${ }^{27}$ C. Mediavilla, op. cit., p. 249.

28 Sobre la reivindicación de los gustos medievales en el diseño gráfico a finales del siglo XIX, véase P. B. Meggs, Historia del diseño gráfico, McGrawHill, México, 1998, p. 169.

${ }^{29}$ P. Bain y P. Shaw, La letra Gótica, Tipo e identidad nacional, Valencia, Campgràfic, 2001, p. 136.

${ }^{30} \mathrm{Ibidem}$

${ }^{31}$ R. Bringhurst, op. cit., pp. 161162.

${ }^{32} \mathrm{~L}$. Solaz, Tim Burton y la construcción del universo fantástico, Tesis doctoral, 2003 [consulta: 15/03/2016], http://roderic.uv.es/bitstream/handle/10550/15280/solaz. pdf?sequence=1. 


\section{REFERENCIAS}

Bain, Peter, and Paul Shaw. 2001. La letra Gótica. Tipo e identidad nacional. Valencia: Campgràfic.

Bringhurst, Robert. 2014. Los elementos del estilo tipográfico. México: Fondo de Cultura Económica.

Calabrese, Omar. 1993. Cómo se lee una obra de arte. Madrid: Cátedra.

Chaves, Norberto. 2002. "Regla, estilo y época. El dilema de los referentes del diseño en una época "sin estilo»." Temes de Disseny, no. 19: 109-117. Accessed April 12, 2016. http://www.raco.cat/index.php/Temes/article/ view/29731/82927

Grangel Studio. 2005. "Grangel Studio, el éxito de la creatividad." Interview. Licencias de actualidad 27: 66-70.

Groupe $\mu$. 1993. Tratado del signo visual. Madrid: Cátedra.

Marcos Arza, Marcos. 2007. Tim Burton. Madrid: Cátedra.

Martín Montesinos, José L. 2014. “De la caligrafía a la tipografía." In ¡La caligrafía vive!, 29-41. València: MuVim-Campgràfic.

Mediavilla, Claude. 2005. Caligrafía. Del signo caligráfico a la pintura abstracta. Valencia: Campgràfic.

Meggs, Philip. B. 1998. Historia del diseño gráfico. México: McGraw-Hill.

Meier, Hans E. 2011. La evolución de la letra. Valencia: Campgràfic.

Navarro Moragas, Francisco J. 2014. "Las formas artísticas de la tipografía y la caligrafía como vehículo histórico de expresión del zeitgeist." Laboratorio de arte 26: 349-372. Accessed 21 January, 2016. https://idus.us.es/xmlui/bitstream/handle/11441/51993/ articulo_17.pdf? sequence $=1$ \&isAllowed=y

Noordzij, Gerrit. 2009. El trazo. Teoría de la escritura. Valencia: Campgràfic.

Pohlen, Joep. 2011. Fuente de letras. Köln: Taschen.

Ramiro, Encarna. 2007. "Cuando ella es el monstruo. La novia cadáver de Tim Burton." Fòrum de recerca 13: 1-14. Accessed 16 February, 2016.

http://repositori.uji.es/xmlui/bitstream/handle/10234/78528/forum_2007_45.pdf?sequence=1

Ribagorda, José María, Javier García del Olmo et. al. 2015. Caligrafía española. El arte de escribir. Madrid: Biblioteca Nacional de España.

Saborit, José. 2018. Lo que la pintura da. Valencia: Pre-textos.

Schapiro, Meyer. 1999. Estilo, artista y sociedad. Teoría y filosofía del arte. Madrid: Tecnos.

Solaz, Lucía. 2003. "Tim Burton y la construcción del universo fantástico." PhD diss., Universitat de València. Departamento de Teoría de los lenguajes. Accessed 15 March, 2016. http:// roderic.uv.es/bitstream/handle/10550/15280/ solaz. pdf? sequence $=1$

Tatarkiewicz, Wladyslaw. 2004. Historia de la estética vol. III. Madrid: Akal.

Trías, Eugenio. 2001. Lo bello y lo siniestro. Barcelona: Ariel.

Vasari, Giorgio. 1568. Vite de'più eccellenti pittori, scultori e architetti vol. I. Roma: Niccolo e Marco Pagliarini. Accessed April 9, 2016. https://books. google.es/books?id=EYgl-hIAfOsC \&printsec=f rontcover\&dq=Vasari+1568\&hl=es\&sa=X\&ved $=0$ ahUKEwiPvui7zMjaAhVGVhQKHdNSCBsQ6AEIKzAA $-\mathrm{v}=$ onepage $\& \mathrm{q}=$ Vasari 1568\&f=false

Zunzunegui, Santos. 1994. Paisajes de la forma. Madrid: Cátedra. 